\title{
Rescue of a pathogenic mutant human glucagon receptor by pharmacological chaperones
}

\author{
Run Yu, Chun-Rong Chen, Xiaohong Liu ${ }^{1}$ and János T Kodra ${ }^{2}$ \\ Division of Endocrinology and Carcinoid and Neuroendocrine Tumor Center, Cedars-Sinai Medical Center, B-131, 8700 Beverly Boulevard, Los Angeles, California 90048, USA \\ ${ }^{1}$ Gilead Sciences, Foster City, California, USA \\ ${ }^{2}$ Novo Nordisk A/S, Novo Nordisk Park, Måløv, Denmark \\ (Correspondence should be addressed to R Yu; Email: run.yu@cshs.org)
}

\begin{abstract}
We have previously demonstrated that a homozygous inactivating P86S mutation of the glucagon receptor (GCGR) causes a novel human disease of hyperglucagonemia, pancreatic $\alpha$-cell hyperplasia, and pancreatic neuroendocrine tumors (Mahvash disease). The mechanisms for the decreased activity of the P86S mutant (P86S) are abnormal receptor localization to the endoplasmic reticulum (ER) and defective interaction with glucagon. To search for targeted therapies for Mahvash disease, we examined whether P86S can be trafficked to the plasma membrane by pharmacological chaperones and whether novel glucagon analogs restore effective receptor interaction. We used enhanced green fluorescent protein-tagged P86S stably expressed in HEK 293 cells to allow fluorescence imaging and western blotting and molecular modeling to design novel glucagon analogs in which alanine 19 was replaced with serine or asparagine. Incubation at $27^{\circ} \mathrm{C}$ largely restored normal plasma membrane localization and normal processing of P86S but osmotic chaperones had no effects. The ER stressors thapsigargin and curcumin partially rescued P86S. The lipophilic GCGR antagonist L-168,049 also partially rescued P86S, so did Cpd 13 and 15 to a smaller degree. The rescued P86S led to more glucagon-stimulated cAMP production and was internalized by glucagon. Compared with the native glucagon, the novel glucagon analogs failed to stimulate more cAMP production by P86S. We conclude that the mutant GCGR is partially rescued by several pharmacological chaperones and our data provide proof-of-principle evidence that Mahvash disease can be potentially treated with pharmacological chaperones. The novel glucagon analogs, however, failed to interact with P86S more effectively.
\end{abstract}

Journal of Molecular Endocrinology (2012) 49, 69-78

\section{Introduction}

The pancreatic islet hormone glucagon is secreted by $\alpha$-cells and regulates blood glucose levels (Quesada et al. 2008, Cryer 2011). Glucagon signals through its G-protein-coupled receptor, glucagon receptor (GCGR), which belongs to the secretin receptor family (Authier \& Desbuquois 2008). We have identified a novel human disease of hyperglucagonemia, $\alpha$-cell hyperplasia, and pancreatic neuroendocrine tumors caused by a homozygous, inactivating GCGR mutation (Mahvash disease) (Yu et al. 2008, Zhou et al. 2009). The natural mutation results in substitution of proline 86 with serine (P86S) in the N-terminal extracellular domain (ECD) of GCGR. One mechanism for the decreased activity of $\mathrm{P} 86 \mathrm{~S}$ is abnormal receptor trafficking (Zhou et al. 2009, Yu et al. 2011a). The WT GCGR is predominantly localized to the plasma membrane; however, only a small portion of P86S is appropriately processed and transported to the plasma membrane while the majority appears to be stranded in the endoplasmic reticulum (ER). Another mechanism appears to be defective interaction with glucagon. We have further demonstrated that GCGR-deficient mice exhibit an identical phenotype to that of Mahvash disease caused by P86S (Yu et al. 2011b). In those mice, a-cell hyperplasia is evident at 3 months, followed by islet dysplasia at 6-7 months, and pancreatic neuroendocrine tumors with $100 \%$ penetrance at 10-12 months. As $\alpha$-cell hyperplasia also occurs in animal models with deficiency of prohormone convertase 2 (resulting in failure to produce glucagon) or treated with GCGR antagonists (Furuta et al. 1997, Petersen \& Sullivan 2001, Qureshi et al. 2004, Winzell et al. 2007, Yan et al. 2009), it is likely that glucagon regulates its own production by negative feedback, the removal of which by GCGR inactivating mutation or deletion causes compensatory hyperglucagonemia and $\alpha$-cell hyperplasia, a precursor to neuroendocrine tumors (Ouyang et al. 2011, Yu et al. 2011b).

Currently, there have been no specific therapies for Mahvash disease (Yu et al. 2008, Ouyang et al. 2011). Somatostatin analogs suppressed glucagon levels in a patient with Mahvash disease but whether they inhibit 
$\alpha$-cell hyperplasia is not clear (Yu et al. 2008). As $\alpha$-cell hyperplasia is reversible after restoring glucagon signaling by supplementing glucagon or withdrawal of antagonists in animal models with deletion of prohormone convertase 2 or treated with GCGR antagonists, respectively (Webb et al. 2002, Gu et al. 2009), $\alpha$-cell hyperplasia is also conceivably reversible in patients with Mahvash disease, if P86S can be rescued. Mutant G-protein-coupled receptors (such as the GnRH receptor and vasopressin type 2 receptor) with abnormal, intracellular localization can be rescued by pharmacological chaperones (Janovick et al. 2002, 2003, Bernier et al. 2004, Robben et al. 2006, Oueslati et al. 2007, Jean-Alphonse et al. 2009). We therefore first examined whether P86S can be trafficked to the plasma membrane by pharmacological chaperones. Encouraged by the rational design of novel ligands for a mutant epithelial growth factor receptor (Denholt $e t$ al. 2009), we also tested whether P86S has improved interaction with novel glucagon analogs designed in silico. Our data demonstrate that $\mathrm{P} 86 \mathrm{~S}$ is partially rescued by pharmacological chaperones and provide proof-of-principle evidence that Mahvash disease can be potentially treated with pharmacological chaperones. The novel glucagon analogs, however, do not interact with P86S more effectively.

\section{Materials and methods}

\section{Cell culture and reagents}

HEK 293 cells stably expressing WT GCGR-EGFP or P86S-EGFP were described previously (Yu et al. 2011a) and grown in DMEM supplemented with $10 \%$ fetal bovine serum at $37^{\circ} \mathrm{C}$ (unless specified otherwise) in a humidified incubator circulated with $5 \% \mathrm{CO}_{2}$. Tunicamycin, DMSO, glycerol, trimethylamine $N$-oxide (TMAO), 4-phenylbutyric acid (PBA), thapsigargin, curcumin, and streptavidin agarose were from Sigma; glucagon and GCGR antagonist L-168,049 from EMD Biosciences (San Diego, CA, USA); and sulfo- $N$-hydroxysulfosuccinimide (NHS)-LC-biotin from Thermo Scientific (Rockford, IL, USA). GCGR antagonists Cpd 13 and Cpd 15 were described previously (Kodra et al. 2008).

\section{Fluorescence microscopy}

Fluorescence microscopy was performed as described previously (Yu et al. 2011a). After treatments, HEK 293 cells expressing WT GCGR-EGFP or P86S-EGFP were fixed with $4 \%$ paraformaldehyde. In most experiments, fixed cells were mounted onto a slide and directly visualized. For immunofluorescent staining, fixed cells were permeabilized with Tween 20 , incubated with mouse anti-N-cadherin (Zymed, South San Francisco, CA, USA), or rabbit anti-calreticulin (Santa Cruz Biotechnology) antibodies and then washed and incubated with rhodamine-labeled goat anti-mouse or anti-rabbit antibody. A TE200 inverted epifluorescence microscope (Nikon, Melville, NY, USA) equipped with relevant fluorescence filters was used to observe the cells. For live cell observation, HEK 293 cells stably expressing WT GCGR-EGFP or P86S-EGFP were grown in flasks with gridded bottom and the same groups of cells were visualized over time with green fluorescence filter using the grids to confirm the identity of cells.

\section{Biotinylation and isolation of cell surface proteins}

Biotinylation and isolation of cell surface proteins were performed according to the manufacturer's recommendation (Thermo Scientific). HEK 293 cells expressing WT GCGR-EGFP or P86S-EGFP were washed, suspended in PBS $(1 \mathrm{ml} / 10 \mathrm{~cm}$ dish with subconfluent cells), and incubated with $0.5 \mathrm{mg}$ sulfo-NHS-LC-biotin at room temperature for $30 \mathrm{~min}$. Cells were then washed and membrane proteins were solubilized in RIPA buffer and incubated with streptavidin agarose at $4^{\circ} \mathrm{C}$ overnight. The agarose beads were washed and bound proteins were eluted with SDS sample buffer.

\section{Western blot and cAMP assay}

Western blot and cAMP assay were described previously (Zhou et al. 2009, Yu et al. 2011a). Briefly, for western blot, cell or protein lysates were resolved in SDS-PAGE and transferred to PVDF membrane. Mouse anti-EGFP (Clontech) (to detect WT GCGR-EGFP or P86S-EGFP) and mouse anti-N-cadherin antibodies were used. For cAMP assay, HEK 293 cells expressing P86S-EGFP were grown in 24-well plates and pretreated with specific conditions. Cells were then incubated with Hank's balanced salt solution containing $1 \mathrm{mM}$ isobutyl methylxanthine (Sigma) and various concentrations of glucagon or novel glucagon analogs at $37^{\circ} \mathrm{C}$ for $1 \mathrm{~h}$. Cells were lysed by freezing and thaw cycles. cAMP was measured with a LANCE cAMP kit (PerkinElmer, Waltham, MA, USA).

\section{Design of novel glucagon analogs}

As the crystal structure of glucagon-bound GCGR has not been resolved, the structures of highly homologous glucagon-like peptide 1 (GLP1) and its receptor (GLP1R) were used to design novel glucagon analogs. GLP1R N-terminal ECD/GLP1 crystal structure coordinates 3IOL (Underwood et al. 2010) was downloaded from Protein Data Bank (PDB) (http://www.rcsb.org/pdb/) 
and analyzed with PyMOL, a molecular graphics system for real-time visualization and rapid generation of high-quality molecular graphics images (DeLano Scientific, San Carlos, CA, USA). The 3IOL structure file was uploaded and the ribbon views created. To illustrate the relative location and possible interactions of the side chains in the mutants, amino acid direct replacement was carried out using the 'mutagenesis' function without energy minimization. Alanine 25 in GLP1 corresponds to alanine 19 in glucagon, and threonine 35 and proline 90 in GLP1R correspond to phenylalanine 31 and proline 86 in GCGR respectively. Amino acid replacement on alanine 19 of the native glucagon was carried out to restore the distances of alanine 19 in glucagon to serine 86 and phenylalanine 31 in GCGR. Peptide 1 was glucagon with alanine 19 replaced with serine and peptide 2 with asparagine; both peptides were synthesized by solid-phase technology (GenScript, Piscataway, NJ, USA).

\section{Results}

\section{Pharmacological chaperones of P86S}

As there are no reliable predictors of chaperones for a given mutant receptor (Conn et al. 2007), we tested potential chaperones of $\mathrm{P} 86 \mathrm{~S}$ based on those that have been used to rescue other mutant G-protein-coupled receptors (Janovick et al. 2002, 2003, Bernier et al. 2004, Robben et al. 2006, Oueslati et al. 2007, Jean-Alphonse et al. 2009). In HEK 293 cells, WT GCGR was predominantly localized on the plasma membrane while P86S was predominantly located in the ER, as indicated by the plasma membrane marker $\mathrm{N}$-cadherin and ER marker calreticulin, respectively, in colocalization experiments (Fig. 1A). Inhibition of glycosylation by tunicamycin changed the localization of the WT GCGR from plasma membrane to cytoplasmic in $\sim 60 \%$ of cells but did not change P86S localization. Osmotic chaperones DMSO (1\%), glycerol (4\%),

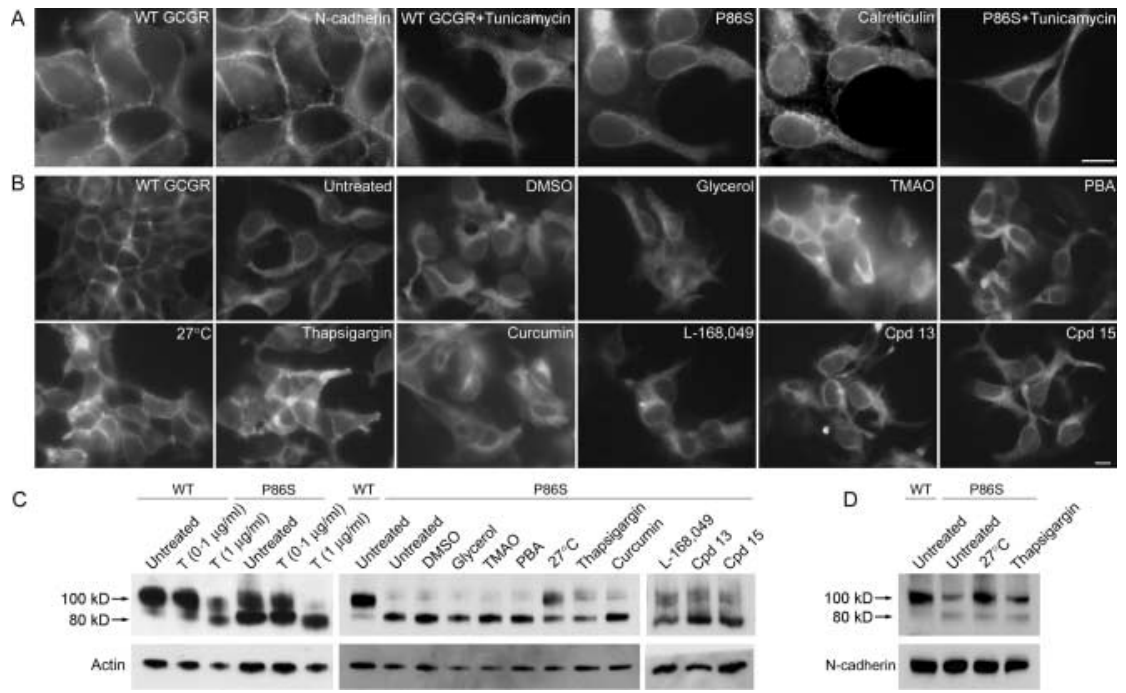

Figure 1 Trafficking of P86S from ER to plasma membrane by chaperones. (A) Localization of WT GCGR-EGFP and P86S-EGFP in HEK 293 cells. Plasma membrane marker $\mathrm{N}$-cadherin and ER marker calreticulin were shown for reference. Note the colocalization of WT GCGR-EGFP and N-cadherin and of P86S-EGFP and calreticulin. Glycosylation inhibitor tunicamycin $(1 \mu \mathrm{g} / \mathrm{ml}, 48 \mathrm{~h})$ changed the localization of WT GCGR-EGFP from plasma membrane to cytoplasmic. (B) Trafficking of P86S shown by fluorescence microscopy. HEK 293 cells expressing the WT GCGR-EGFP (WT GCGR) or the P86S-EGFP without specific treatment (untreated) were shown for comparison. HEK 293 cells stably expressing P86S-EGFP were treated with 1\% DMSO, 4\% glycerol, $150 \mathrm{mM}$ TMAO, $5 \mathrm{mM}$ PBA, at $27^{\circ} \mathrm{C}$, with glucagon receptor antagonist L-168,049 $(1.4 \mu \mathrm{M})$, Cpd $13(10 \mu \mathrm{M})$, or Cpd $15(10 \mu \mathrm{M})$ overnight, or thapsigargin $(1 \mu \mathrm{M})$ or curcumin $(1 \mu \mathrm{M})$ for $7 \mathrm{~h}$. Cells were fixed and fluorescent images were taken. (C) Processing of WT GCGR-EGFP and P86S-EGFP. HEK 293 cells expressing WT GCGR-EGFP or P86S-EGFP were treated similarly as in $A$ and $B$ and lysed and subjected to western blotting with antibodies to EGFP or actin. (D) Cell surface WT GCGR-EGFP or P86S-EGFP after chaperone treatments. Live HEK 293 cells expressing WT GCGR-EGFP or P86S-EGFP without specific treatment and cells expressing P86S-EGFP incubated at $27^{\circ} \mathrm{C}$ for $24 \mathrm{~h}$ or thapsigargin $(1 \mu \mathrm{M})$ for $7 \mathrm{~h}$ were labeled with biotin, lysed, and biotinylated proteins resolved on SDS-PAGE and WT GCGR-EGFP or P86S-EGFP detected by western blot. Cell surface protein $\mathrm{N}$-cadherin was shown as loading control. Bar, $10 \mu \mathrm{m}$. 
TMAO (130-200 mM), and PBA (3-10 mM) had no visible effects on P86S localization after overnight incubation (16-20 h) (Fig. 1B). Incubation at $27^{\circ} \mathrm{C}$ largely restored plasma membrane localization of P86S. ER stressors thapsigargin and curcumin have been shown to rescue mutant G-protein-coupled receptors; the mechanism appears to be related to the increase in intracellular calcium levels induced by ER stressors (Robben et al. 2006, Oueslati et al. 2007). In our experiments, thapsigargin had some effects on restoring P86S plasma membrane localization but curcumin had a smaller effects (Fig. 1B). As lipophilic receptor antagonists are often chaperones of mutant receptors, we tested three lipophilic GCGR antagonists for their chaperone activity. L-168,049 treatment resulted in P86S plasma membrane localization in some cells but Cpd 13 and 15 had no visible effects on P86S localization (Fig. 1B). Corresponding to the predominant plasma membrane localization of WT GCGR and predominant ER localization of P86S, WT GCGREGFP migrated mainly as an $100-\mathrm{kD}$ band on western blot $(83.5 \pm 3.5 \%$ of total amounts by densitometry), indicating the $100-\mathrm{kD}$ band as the mature form (Fig. 1C). P86S-EGFP migrated mainly as a smaller, 80-kD band on western blot, presumably an immature form, with diminished amounts of the mature form $(12.9 \pm 0.7 \%$ by densitometry). Consistent with the results of microscopic observation, the glycosylation inhibitor tunicamycin at a higher concentration decreased the quantity of the mature $100-\mathrm{kD}$ band in cells expressing either WT-GCGR-EGFP or P86S-EGFP (Fig. 1C). The osmotic chaperones, DMSO, glycerol, TMAO, and PBA did not change the ratio of the mature vs immature form of P86S. Incubation at $27^{\circ} \mathrm{C}$ resulted in a significant increase in the mature form of P86S (to $76 \cdot 8 \pm 2 \cdot 6 \%$ by densitometry), so did the ER stressors thapsigargin and curcumin but to a lesser degree (to $48 \cdot 7 \pm 2 \cdot 4$ and $46 \cdot 4 \pm 1 \cdot 4 \%$ by densitometry respectively). Lipophilic GCGR antagonists also increased the ratio of mature vs immature forms of P86S to various degrees with L-168,049 having the biggest effect. Thus, microscopic and biochemical studies consistently demonstrated that low temperature, ER stressors, and lipophilic GCGR antagonists facilitate P86S maturation and trafficking to the plasma membrane while osmotic chaperones have no effects on those processes.

To confirm the subcellular localization of WT GCGR and P86S and the trafficking of P86S to the plasma membrane by chaperones, live HEK 293 cells expressing WT GCGR-EGFP or P86S-EGFP were labeled with biotin (which binds to cell surface proteins) and biotinylated proteins isolated and detected by western blot (Fig. 1D). Consistent with the intracellular P86S localization, levels of biotinylated P86S-EGFP (on cell surface) in untreated cells were much lower than those of WT GCGR-EGFP, which was localized on the cell surface by microscopy (shown earlier); incubation at $27^{\circ} \mathrm{C}$ and thapsigargin increased the levels of biotinylated P86S-EGFP, in agreement with P86S trafficking to the cell surface by those two chaperones.

\section{Mechanisms for P86S trafficking by chaperones}

We used live cell imaging to observe the trafficking of P86S by the two most effective chaperones, low temperature and thapsigargin. Starting only $1 \mathrm{~h}$ after
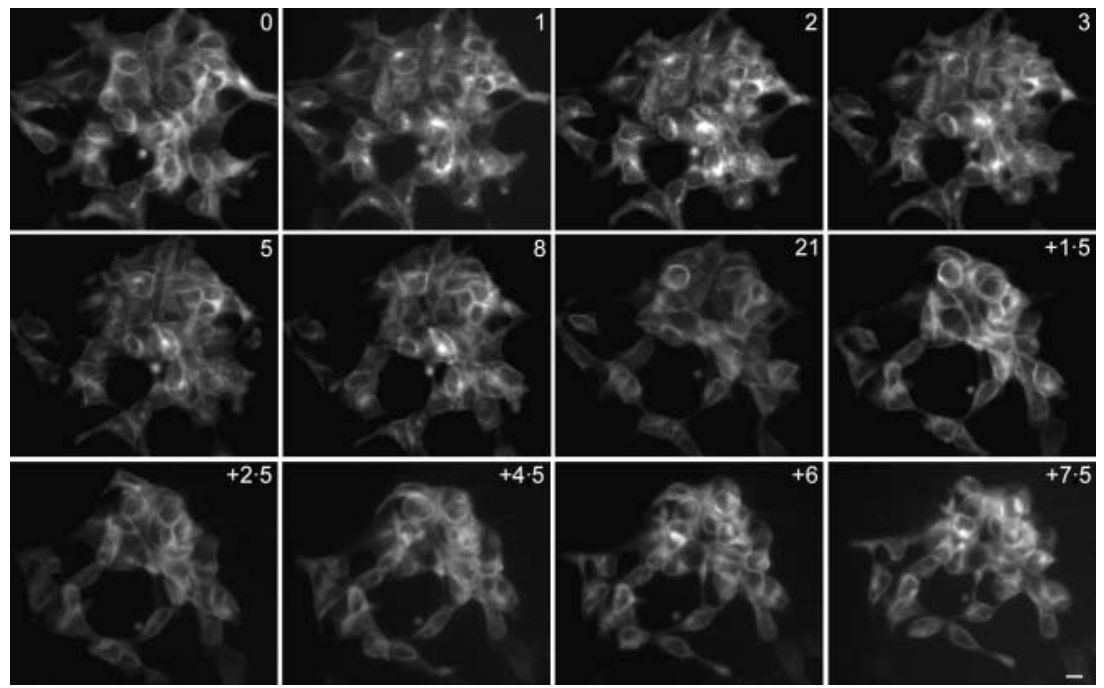

Figure 2 Time course of rescue by low temperature under live cell imaging. HEK 293 cells stably expressing P86S-EGFP were incubated at $27^{\circ} \mathrm{C}$ for $21 \mathrm{~h}$ and then at $37^{\circ} \mathrm{C}$ for $7.5 \mathrm{~h}$. Shown are the same live cells observed at the indicated times (in hours). A plus sign denotes incubation at $37^{\circ} \mathrm{C}$ after incubation at $27^{\circ} \mathrm{C}$. Bar, $10 \mu \mathrm{m}$. 

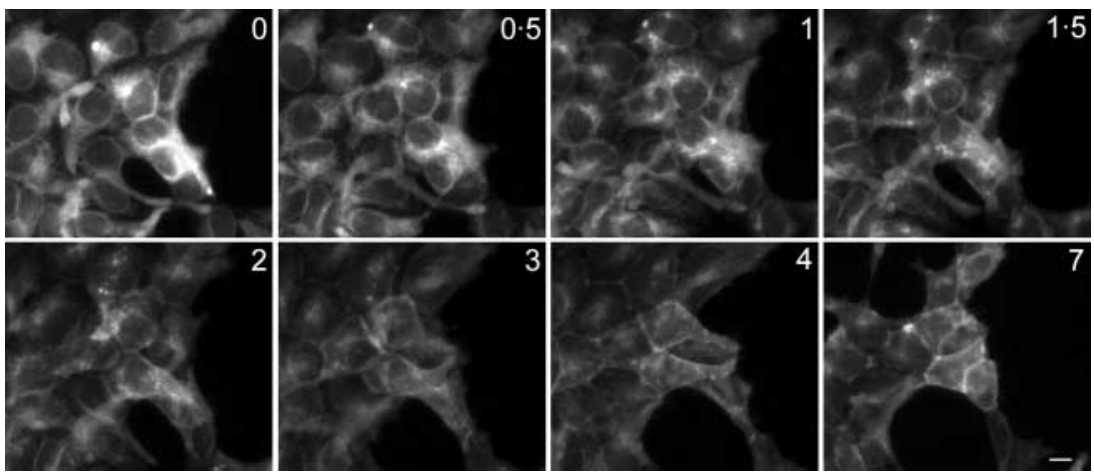

Figure 3 Time course of rescue by thapsigargin under live cell imaging. HEK 293 cells stably expressing P86S-EGFP were treated with $1 \mu \mathrm{M}$ thapsigargin for $7 \mathrm{~h}$. Shown are the same live cells observed at the indicated times (in hours). Bar, $10 \mu \mathrm{m}$.

cells were incubated at $27^{\circ} \mathrm{C}$, most cells developed coarse granular aggregates of P86S-EGFP (Fig. 2). Significant plasma membrane localization began to appear at $2 \mathrm{~h}$, gradually spreading to more cells over time; at $8 \mathrm{~h}$, the majority of cells already exhibited plasma membrane P86S localization. Upon warming to $37^{\circ} \mathrm{C}$, plasma membrane localization persisted as long as $2.5 \mathrm{~h}$ but ER localization gradually became more evident and dominated at $7.5 \mathrm{~h}$ after warming. Similar P86S-EGFP aggregates were also seen in cells treated with thapsigargin before plasma membrane localization became predominant (Fig. 3). We have previously shown that $\mathrm{P} 86 \mathrm{~S}$ and ER residential protein calreticulin colocalize in HEK 293 cells (Yu et al. 2011a). As calreticulin is a molecular chaperone (Michalak et al. 2009), we tested whether calreticulin and aggregated P86S colocalize. Immunostaining of calreticulin in cells treated with low temperature or thapsigargin for $2 \mathrm{~h}$ showed that the P86SEGFP aggregates and calreticulin did not colocalize, suggesting that calreticulin is not a molecular chaperone of P86S (Fig. 4).

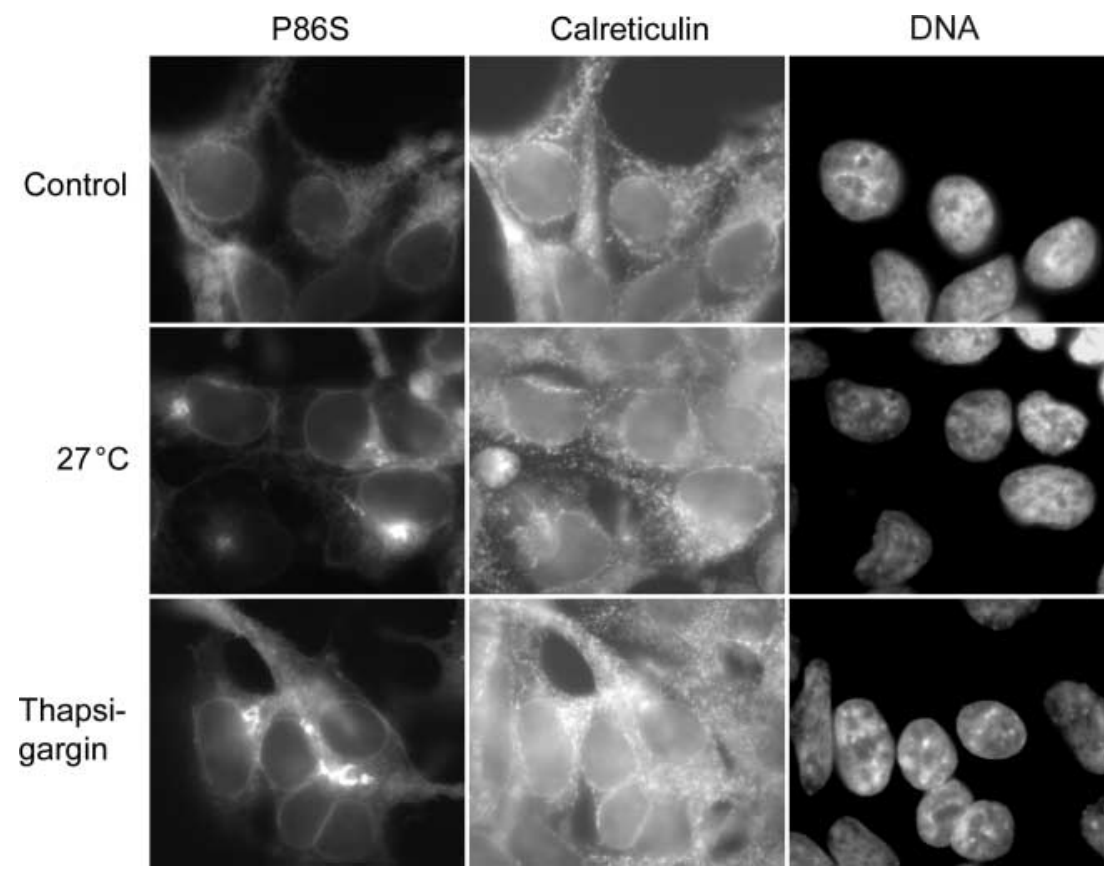

Figure 4 Calreticulin is not a P86S molecular chaperone. HEK 293 cells stably expressing P86S-EGFP were incubated at $27^{\circ} \mathrm{C}$ or treated with $1 \mu \mathrm{M}$ thapsigargin for $2 \mathrm{~h}$. Cells were fixed and immunostained for calreticulin (middle column) and counterstained with Hoechst 33352 (right column). Note that in cells incubated at $27^{\circ} \mathrm{C}$ or treated with thapsigargin, the aggregates of P86S-EGFP fluorescence (left column) and calreticulin fluorescence do not overlap. Bar, $10 \mu \mathrm{m}$. 


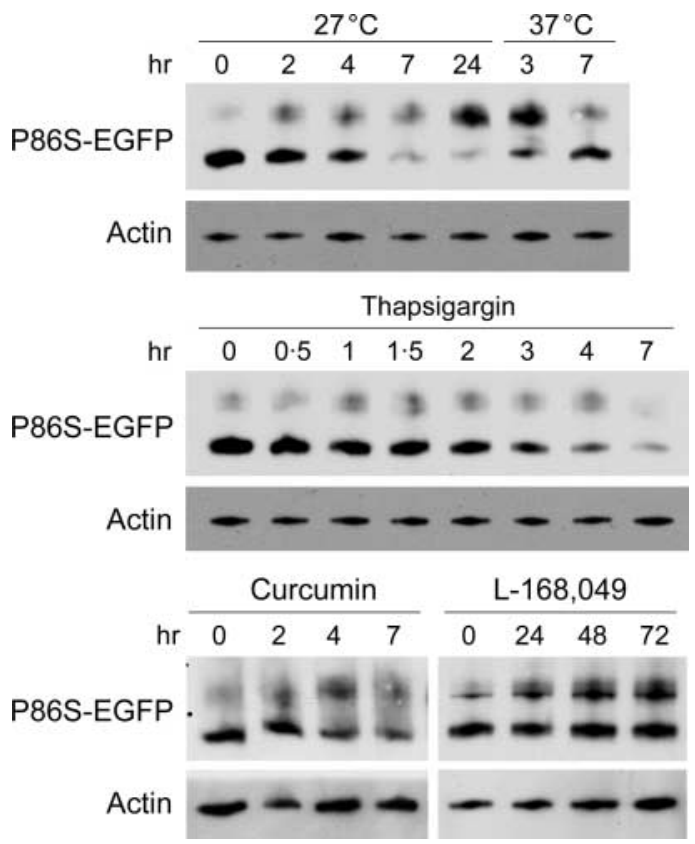

Figure 5 Maturation of P86S by chaperones. HEK 293 cells stably expressing P86S-EGFP were incubated at $27^{\circ} \mathrm{C}$ for $2-24 \mathrm{~h}$ and then at $37^{\circ} \mathrm{C}$ for $3-7 \mathrm{~h}$ or treated with $1 \mu \mathrm{M}$ thapsigargin or curcumin for $7 \mathrm{~h}$ or glucagon antagonist L-168,049 for 24-72 $\mathrm{h}$. Cells were lysed at the indicated time and subjected to SDS-PAGE and western blotting with anti-EGFP or anti-actin.

Parallel western blot experiments on cells treated with low temperature showed that the amount of mature form of P86S increased at $2 \mathrm{~h}$ with a simultaneous decrease in that of the immature form (Fig. 5). At $7 \mathrm{~h}$, however, the total amount of P86S, especially the immature form, was significantly decreased compared with that at the beginning of low-temperature treatment with similar levels of the mature form, suggesting degradation of the immature form of P86S-EGFP during the $4-7 \mathrm{~h}$ after low-temperature treatment. As the total amount of P86S-EGFP returned to pretreatment levels at $24 \mathrm{~h}$, it appeared that the newly synthesized P86S-EGFP was correctly processed at low temperature. Western blot also confirmed that the mature form remained on the plasma membrane even at $3 \mathrm{~h}$ after warming. Thapsigargin and curcumin treatments also increased the mature form of P86S in 2-4 h. Similar to that in cells treated at low temperature, the immature form underwent significant degradation during the 4-7 h of treatment. We could not carry out the experiments longer due to toxicities of thapsigargin and curcumin. The lipophilic GCGR antagonist L-168,049 increased the amount of mature P86S-EGFP without a significant decrease in the immature form so that P86S-EGFP remained predominantly in the immature form, explaining the apparent lack of clear P86S-EGFP plasma membrane localization after L-168,049 treatment.

\section{Function of trafficked P86S}

We tested whether the trafficked P86S would be functional by cAMP production and receptor internalization (Figs 6 and 7). Compared with HEK 293 cells expressing P86S-EGFP preincubated at the normal $37^{\circ} \mathrm{C}$ (with P86S stranded in the ER and only 12.9\% on the plasma membrane as shown earlier), cells preincubated at $27^{\circ} \mathrm{C}$ for $24 \mathrm{~h}$ (with $76.8 \%$ of $\mathrm{P} 86 \mathrm{~S}$ on plasma membrane) produced significantly more cAMP upon stimulation by glucagon at $10-100 \mathrm{nM}$ (Fig. 6). Similarly, in another experiment, cells pretreated with thapsigargin (48.7\% of P86S on plasma membrane) produced significantly more cAMP upon stimulation by $100 \mathrm{nM}$ glucagon. In parallel experiments, HEK 293 cells expressing P86S-EGFP were
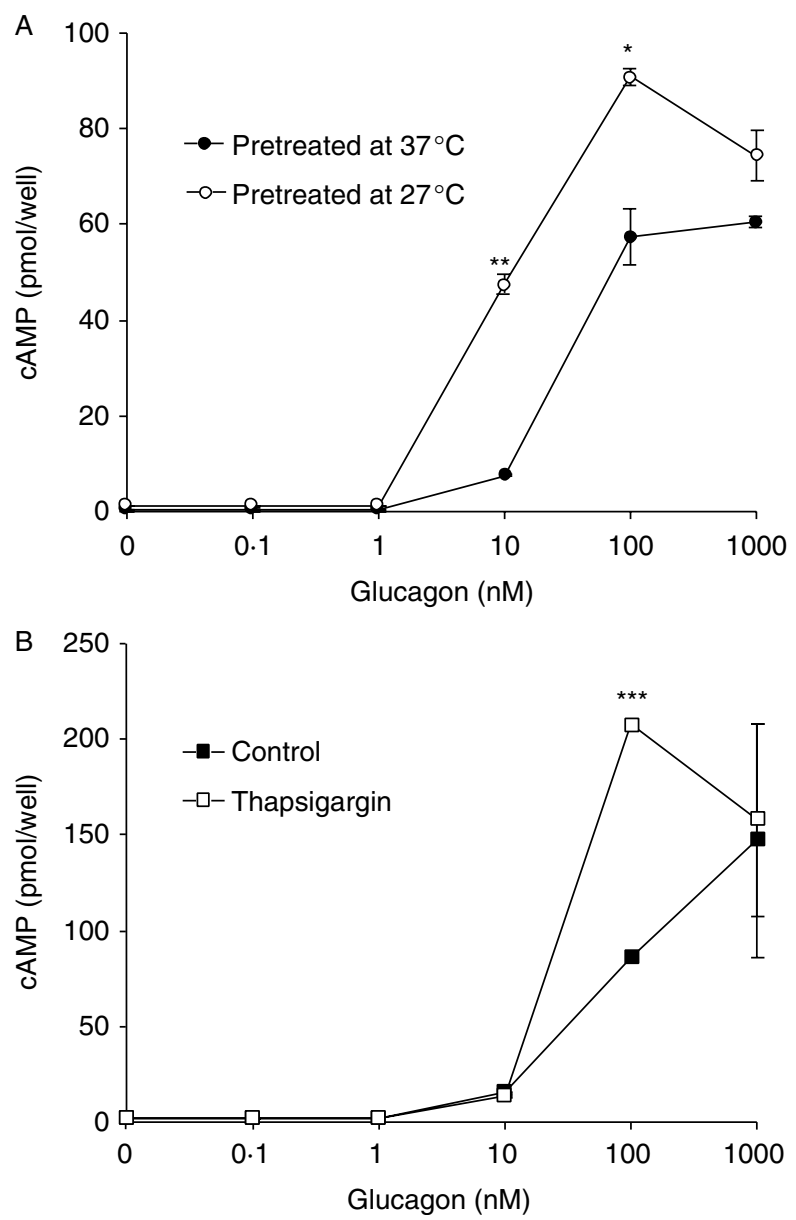

Figure 6 Signaling of rescued P86S by glucagon. (A) HEK 293 cells stably expressing P86S-EGFP were incubated at $37^{\circ} \mathrm{C}$ or $27^{\circ} \mathrm{C}$ for $24 \mathrm{~h}$ and then at $37^{\circ} \mathrm{C}$ for $1 \mathrm{~h}$ in the presence of vehicle $(0.01 \mathrm{M} \mathrm{HCl}, 1: 1000)$ or glucagon at increasing concentrations. (B) In another experiment, HEK 293 cells stably expressing P86SEGFP were treated with $1 \mu \mathrm{M}$ thapsigargin for $6 \mathrm{~h}$ followed by incubation with vehicle or glucagon for another hour. Cells were lysed and cAMP production was measured. ${ }^{\star} P<0.05$; ${ }^{\star \star} P<0.01$; ${ }_{* \star *} P<0.001$. 


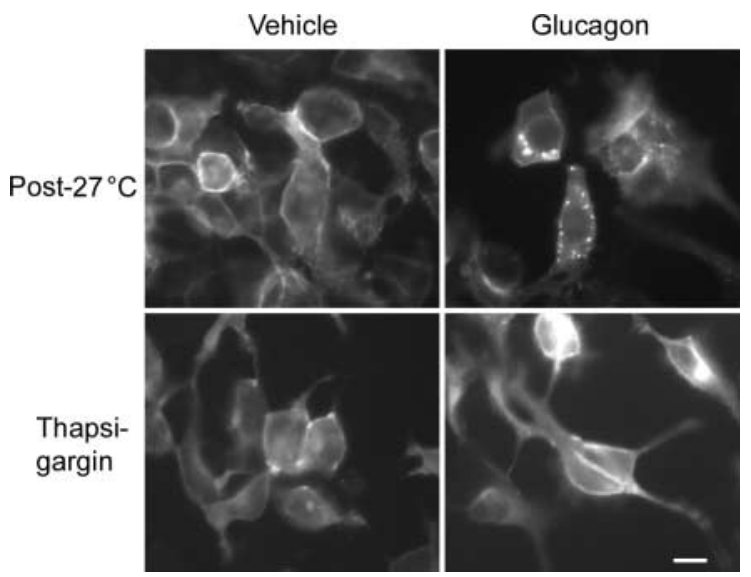

Figure 7 Internalization of rescued P86S by glucagon. HEK 293 cells stably expressing P86S-EGFP were incubated at $27^{\circ} \mathrm{C}$ for $24 \mathrm{~h}$ and then at $37^{\circ} \mathrm{C}$ for $1 \mathrm{~h}$ in the presence of vehicle $(0.01 \mathrm{M} \mathrm{HCl}, 1: 1000)$ or glucagon $(1 \mu \mathrm{M})$ or treated with $1 \mu \mathrm{M}$ thapsigargin for $6 \mathrm{~h}$ followed by incubation with vehicle or glucagon for another hour. Bar, $10 \mu \mathrm{m}$.

pretreated at $27^{\circ} \mathrm{C}$ for $24 \mathrm{~h}$ and warmed to $37^{\circ} \mathrm{C}$ and treated with vehicle or glucagon (Fig. 7). The plasma membrane P86S-EGFP was internalized by glucagon like the WT GCGR. P86S-EGFP trafficked by thapsigargin did not internalize upon glucagon treatment.

\section{Design of novel glucagon analogs}

Glucagon and GCGR are highly homologous to GLP1 and GLP1 receptor (GLP1R). GCGR has not been resolved by crystallography but the N-terminal ECD of GLP1R bound with GLP1 has. Proline 90 in GLP1R (corresponding to proline 86 in GCGR) is in the binding pocket of GLP1R and GLP1 and interacts with alanine 25 of GLP1 (corresponding to alanine 19 in glucagon) (Runge et al. 2008). As replacing proline 86 in GCGR with serine decreases receptor activity, we hypothesized that changing alanine 19 in glucagon to another amino acid residue potentially restores the glucagon-stimulated signal transduction of P86S. Based on molecular modeling (see Materials and methods), two novel glucagon analogs, peptide 1 and peptide 2, were synthesized, in which alanine 19 was replaced with serine or asparagine respectively (Fig. 8). The free hydroxyl group in serine and amino group in asparagine may also form a hydrogen bond with serine 86 in P86S.

\section{Testing the potency of novel glucagon analogs}

We tested whether the two rationally designed analogs would augment the signal transduction of P86S (Fig. 9). Compared with the native glucagon, both peptide 1 and peptide 2 were less effective in stimulating cAMP production by cells expressing P86S-EGFP either preincubated at $37^{\circ} \mathrm{C}$ (ER-stranded P86S) or $27^{\circ} \mathrm{C}$ (rescued P86S). Interestingly, cAMP production by cells pretreated at $27^{\circ} \mathrm{C}$ was invariably larger, regardless of which glucagon species was used, supporting that low temperature rescues the P86S function.

\section{Discussion}

Natural mutations of G-protein-coupled receptors are rare but cause various inherited or sporadic human diseases (Spiegel \& Weinstein 2004, Tao 2006). Pathogenic mutations inappropriately activate or inactivate the receptors harboring them. The loss of receptor function by the inactivating mutations can be due to one or more abnormalities in the four mechanisms: receptor synthesis, receptor trafficking to the plasma membrane, ligand binding, and receptor activation of $\mathrm{G}$ proteins (Tao 2006). Among those, abnormal receptor trafficking is the most common mechanism for receptor inactivation. We have previously described for the first time an inactivating
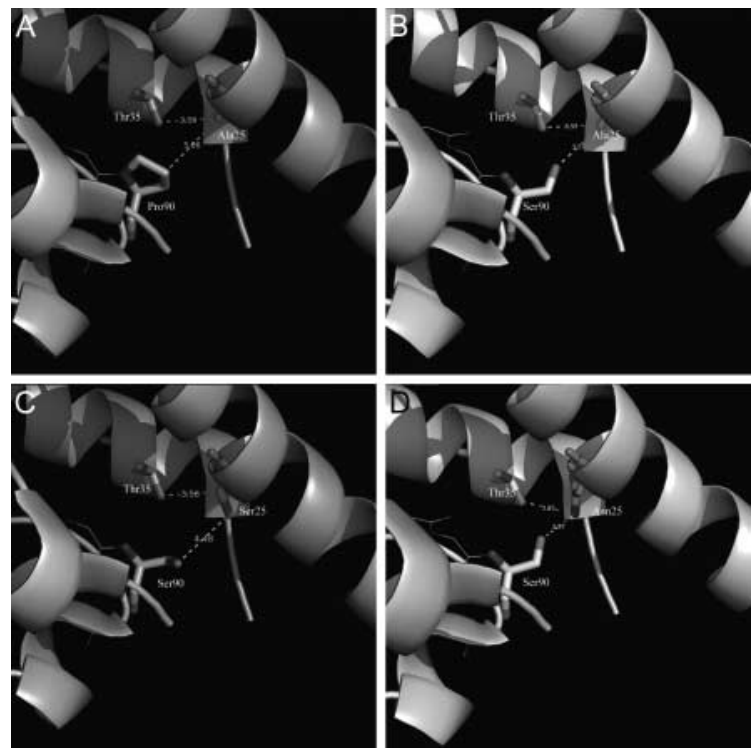

Figure 8 Design of novel glucagon analogs based on the crystal structure of GLP1 and GLP1R N-terminal ECD. Glucagon and GCGR are highly homologous to GLP1 and GLP1R. Shown is ribbon diagrams of GLP1 bound with GLP1R ECD. The graph was created with the program PyMOL for structure 3IOL. (A) The WT GLP1R ECD (left) bound with GLP1 (right). Side chains for residue Pro90 and Thr35 (from GLP1R) and Ala25 (from GLP1) are illustrated as sticks. (B) Mutant GLP1R ECD with Pro90 replaced with Ser (P90S) as in the P86S mutation in GCGR (left) bound with GLP1 (right). (C) P90S GLP1R ECD bound with a hypothetical GLP1 with Ala25 (corresponding to Ala19 in glucagon) replaced with Ser. (D) P90S GLP1R ECD bound with a hypothetical GLP1 with Ala25 replaced with Asn. Residues were replaced with the mutagenesis function in PyMOL program without energy minimization. 

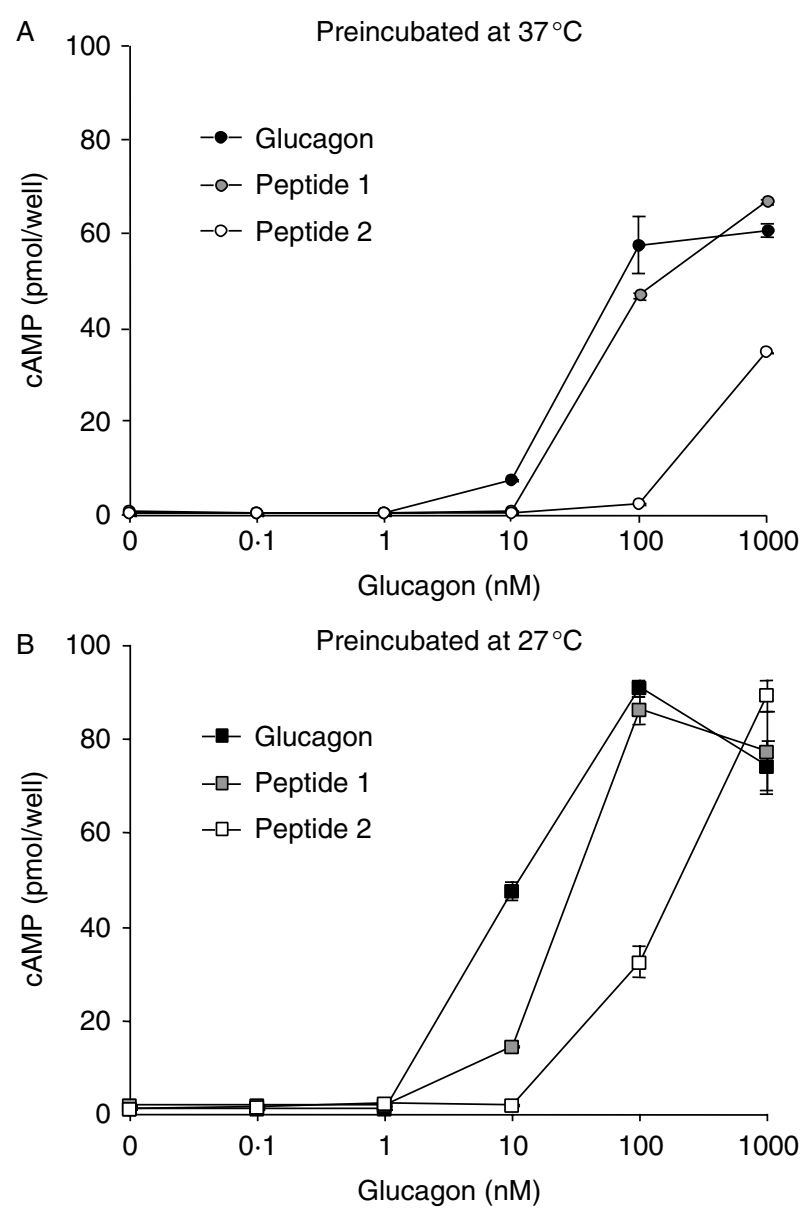

Figure 9 Signaling of rescued P86S stimulated by novel glucagon analogs. HEK 293 cells stably expressing P86S-EGFP were incubated at $37^{\circ} \mathrm{C}(\mathrm{A})$ or $27^{\circ} \mathrm{C}(\mathrm{B})$ for $24 \mathrm{~h}$ and then at $37^{\circ} \mathrm{C}$ for $1 \mathrm{~h}$ in the presence of vehicle $(0.01 \mathrm{M} \mathrm{HCl}, 1: 1000)$, glucagon, and novel glucagon analog 1 (peptide 1) or analog 2 (peptide 2) at increasing concentrations. Cells were lysed and cAMP production was measured.

mutation (P86S) of the human GCGR that causes a novel human disease of hyperglucagonemia without glucagonoma syndrome, hypoglycemia, pancreatic $\alpha$-cell hyperplasia, and pancreatic neuroendocrine tumors (Mahvash disease) (Yu et al. 2008, Zhou et al. 2009). It is interesting to note that the most severe feature of Mahvash disease, pancreatic neuroendocrine tumors, is an indirect effect of GCGR inactivation, namely, compensatory $\alpha$-cell hyperplasia (Ouyang et al. 2011). The main mechanism of decreased P86S functionality is abnormal receptor trafficking: P86S is stranded in the ER rather than localized on the plasma membrane (Yu et al. 2011a). The second mechanism appears to be defective interaction with glucagon (Zhou et al. 2009). As $\alpha$-cell hyperplasia is reversible in other circumstances (Webb et al. 2002, Gu et al. 2009) and there are no specific treatments for Mahvash disease (Yu et al. 2008, Ouyang et al. 2011), rescuing
P86S function by chaperones or novel ligands may be a viable treatment strategy, which has the potential to revert the hypoglycemia and $\alpha$-cell hyperplasia.

Our results demonstrate that on principle, P86S can be at least partially rescued by chaperones. Low temperature largely restored P86S plasma membrane localization while ER stressors and lipophilic GCGR antagonists partially achieved that, but osmotic chaperones had no effects. Our data further indicate that the rescued P86S can be functional as shown by the increased glucagon-stimulated cAMP production in cells with rescued $\mathrm{P} 86 \mathrm{~S}$ and the normal internalization of the rescued P86S by low temperature. It should not be taken for granted that P86S can be rescued. Whether a mutant receptor can be rescued by pharmacological chaperones is unpredictable and a mutant receptor is more often than not unrescuable; for example, only one of nine ER-stranded mutant vasopressin type 2 receptors is rescued even though most of them only have single amino acid mutations (Robben et al. 2006). That P86S is at least partially rescuable suggests that pharmacological chaperones are a potential treatment for Mahvash disease. It is not surprising that the chaperones had various effects on P86S rescue as the efficacy of pharmacological chaperones is also not quite predictable as shown by the variable efficacies of peptidomimetic chaperones on the same mutant GnRH receptor (Janovick et al. 2003).

Our study also elucidates to some degree the mechanisms for which pharmacological chaperones rescue P86S. Although the specifics of normal GCGR trafficking are not known, it is generally held that nascent proteins in the ER are folded with the help of molecular chaperones and adopt a particular 3-dimensional structure that guides their trafficking to distinct subcellular locations, including the plasma membrane (Conn et al. 2007). The seven transmembrane domains of the rat GCGR are required for cell surface expression, but the N-terminal ECD is not, nor are the four putative N-linked glycosylation sites on the $\mathrm{N}$ terminus (Unson et al. 1995). By contrast, we show in the current work that glycosylation inhibitor partially prevents normal plasma membrane localization of human GCGR. The role of GCGR glycosylation in receptor localization is thus not clear and needs to be clarified in future studies. Our data demonstrate that both WT GCGR and P86S exist in two forms, a mature larger form residing on the plasma membrane (predominant form of WT GCGR) and an immature smaller form stranded in the ER (predominant form of P86S), similar to mutant vasopressin type 2 receptors (Bernier et al. 2004). Upon low-temperature or thapsigargin treatment, the immature P86S would accumulate in aggregates that are devoid of calreticulin, a common molecular chaperone, with a concurrent increase in the amounts of mature P86S and a decrease 
in the amounts of immature P86S. The functions of the P86S aggregates are not clear but may be important for degradation or maturation of immature P86S. The mechanisms for low temperature and ER stressors to rescue misfolded receptors are not very clear but may involve modulating interaction with molecular chaperones and an increase in intracellular calcium levels respectively (Oueslati et al. 2007, Filipeanu et al. 2011).

The ideal pharmacological chaperone should be efficacious, specific, and nontoxic (Conn et al. 2007). Although low temperature and ER stressors are efficacious in restoring the correct localization of P86S, they are nonspecific, and impractical and could be toxic as shown in the cases of thapsigargin and curcumin. The less efficacious lipophilic GCGR antagonists are probably more specific with unknown toxic profile. To search for more clinically useful pharmacological chaperones of P86S, two approaches may be useful: high-throughput screening of chemical libraries and a more targeted approach based on the molecular mechanisms for GCGR trafficking; the former has been used to derive pharmacological chaperones for mutant GnRH receptors and vasopressin type 2 receptors (Janovick et al. 2011). The HEK 293 cells stably expressing P86S-EGFP can form the basis for large-scale screening.

Novel ligands specifically and rationally designed for a mutant receptor, our second approach to rescue P86S function, did not achieve their goal. In silico design of 'magic bullets' for drug targets has been successful in some cases (Costanzi et al. 2005, Durdagi et al. 2009). At first look, P86S would be an ideal target for in silico design of novel ligands. P86S exhibits defective interaction with glucagon and the mutated amino acid residue lies in the ECD where GCGR normally interacts with glucagon (Unson et al. 2002, Yu et al. 2008), and the crystal structure of homologous GLP1R N-terminal ECD has been resolved, which shows that the corresponding proline in GLP1R (mutated to serine in P86S) is part of the binding pocket (Runge et al. 2008, Underwood $e$ al. 2010). In addition, the novel glucagon analogs would potentially be an example of a personalized drug. The in silico design without crystal structure of GCGR binding with glucagon, however, is intrinsically theoretical and requires experimental confirmation. It is not clear why the novel glucagon analogs did not interact with P86S more effectively but potential explanations are substantial differences in the 3-dimensional structure between GCGR and GLP1R and inapplicable assumptions of the software used for in silico design. Even though our specific glucagon analogs failed, the in silico modeling is still a valid and economical approach to rationally design novel drugs. It is conceivable that after the GCGR crystal structure is resolved, novel and rationally designed glucagon analogs or small molecules may prove invaluable in treating patients with P86S mutation.
In summary, we have demonstrated that the P86S mutant GCGR is partially rescued by several pharmacological chaperones with restoration of receptor function to some degree. Our data provide proof-of-principle evidence that Mahvash disease can be potentially treated with pharmacological chaperones. The novel glucagon analogs, however, failed to interact with P86S more effectively.

\section{Declaration of interest}

The authors declare that there is no conflict of interest that could be perceived as prejudicing the impartiality of the research reported.

\section{Funding}

The work was supported by National Institutes of Health grant DK071870 (R Y) and Cedars-Sinai Medical Center.

\section{Author contribution statement}

The study was designed by R Y, C-R C, and X L; experiments were carried out by R Y, C-R C, and X L; and data were analyzed by R Y, C-R C, X L, and J T K. The manuscript was drafted by R Y and approved by all authors.

\section{Acknowledgements}

The authors thank Dr Milton T Stubbs for help in designing the novel glucagon analogs.

\section{References}

Authier F \& Desbuquois B 2008 Glucagon receptors. Cellular and Molecular Life Sciences 65 1880-1899. (doi:10.1007/s00018008-7479-6)

Bernier V, Lagacé M, Lonergan M, Arthus MF, Bichet DG \& Bouvier M 2004 Functional rescue of the constitutively internalized V2 vasopressin receptor mutant $\mathrm{R} 137 \mathrm{H}$ by the pharmacological chaperone action of SR49059. Molecular Endocrinology 18 2074-2084. (doi:10.1210/me.2004-0080)

Conn PM, Ulloa-Aguirre A, Ito J \& Janovick JA 2007 G protein-coupled receptor trafficking in health and disease: lessons learned to prepare for therapeutic mutant rescue in vivo. Pharmacological Reviews 59 225-250. (doi:10.1124/pr.59.3.2)

Costanzi S, Joshi BV, Maddileti S, Mamedova L, Gonzalez-Moa MJ, Marquez VE, Harden TK \& Jacobson KA 2005 Human P2Y(6) receptor: molecular modeling leads to the rational design of a novel agonist based on a unique conformational preference. Journal of Medicinal Chemistry 48 8108-8111. (doi:10.1021/jm050911p)

Cryer PE 2011 Glucagon in the pathogenesis of hypoglycemia and hyperglycemia in diabetes. Endocrinology 153 1039-1048. (doi:10.1210/en.2011-1499)

Denholt CL, Hansen PR, Pedersen N, Poulsen HS, Gillings N \& Kjaer A 2009 Identification of novel peptide ligands for the cancer-specific receptor mutation EFGRvIII using a mixture-based synthetic combinatorial library. Biopolymers 91 201-206. (doi:10.1002/bip.21117) 
Durdagi S, Supuran CT, Strom TA, Doostdar N, Kumar MK, Barron AR, Mavromoustakos T \& Papadopoulos MG 2009 In silico drug screening approach for the design of magic bullets: a successful example with anti-HIV fullerene derivatized amino acids. Journal of Chemical Information and Modeling 49 1139-1143. (doi:10.1021/ ci900047s)

Filipeanu CM, de Vries R, Danser AH \& Kapusta DR 2011 Modulation of $\alpha(2 \mathrm{C})$ adrenergic receptor temperature-sensitive trafficking by HSP90. Biochimica et Biophysica Acta 1813 346-357. (doi:10.1016/j. bbamcr.2010.11.020)

Furuta M, Yano H, Zhou A, Rouillé Y, Holst JJ, Carroll R, Ravazzola M, Orci L, Furuta H \& Steiner DF 1997 Defective prohormone processing and altered pancreatic islet morphology in mice lacking active SPC2. PNAS 94 6646-6651. (doi:10.1073/pnas.94.13.6646)

Gu W, Yan H, Winters KA, Komorowski R, Vonderfecht S, Atangan L, Sivits G, Hill D, Yang J, Bi V et al. 2009 Long-term inhibition of the glucagon receptor with a monoclonal antibody in mice causes sustained improvement in glycemic control, with reversible $\alpha$-cell hyperplasia and hyperglucagonemia. Journal of Pharmacology and Experimental Therapeutics 331 871-881. (doi:10.1124/jpet.109.157685)

Janovick JA, Maya-Nunez G \& Conn PM 2002 Rescue of hypogonadotropic hypogonadism-causing and manufactured GnRH receptor mutants by a specific protein-folding template: misrouted proteins as a novel disease etiology and therapeutic target. Journal of Clinical Endocrinology and Metabolism 87 3255-3262. (doi:10.1210/jc.87.7.3255)

Janovick JA, Goulet M, Bush E, Greer J, Wettlaufer DG \& Conn PM 2003 Structure-activity relations of successful pharmacologic chaperones for rescue of naturally occurring and manufactured mutants of the gonadotropin-releasing hormone receptor. Journal of Pharmacology and Experimental Therapeutics 305 608-614. (doi:10.1124/jpet.102.048454)

Janovick JA, Park BS \& Conn PM 2011 Therapeutic rescue of misfolded mutants: validation of primary high throughput screens for identification of pharmacoperone drugs. PLOS ONE 6 e22784. (doi:10.1371/journal.pone.0022784)

Jean-Alphonse F, Perkovska S, Frantz MC, Durroux T, Méjean C, Morin D, Loison S, Bonnet D, Hibert M, Mouillac B et al. 2009 Biased agonist pharmacochaperones of the AVP V2 receptor may treat congenital nephrogenic diabetes insipidus. Journal of the American Society of Nephrology 20 2190-2203. (doi:10.1681/ASN.2008121289)

Kodra JT, Jørgensen AS, Andersen B, Behrens C, Brand CL, Christensen IT, Guldbrandt M, Jeppesen CB, Knudsen LB, Madsen P et al. 2008 Novel glucagon receptor antagonists with improved selectivity over the glucose-dependent insulinotropic polypeptide receptor. Journal of Medicinal Chemistry 51 5387-5396. (doi:10.1021/jm7015599)

Michalak M, Groenendyk J, Szabo E, Gold LI \& Opas M 2009 Calreticulin, a multi-process calcium-buffering chaperone of the endoplasmic reticulum. Biochemical Journal 417 651-666. (doi:10.1042/BJ20081847)

Oueslati M, Hermosilla R, Schönenberger E, Oorschot V, Beyermann M, Wiesner B, Schmidt A, Klumperman J, Rosenthal W \& Schülein R 2007 Rescue of a nephrogenic diabetes insipiduscausing vasopressin V2 receptor mutant by cell-penetrating peptides. Journal of Biological Chemistry 282 20676-20685. (doi:10.1074/jbc.M611530200)

Ouyang D, Dhall D \& Yu R 2011 Pathologic pancreatic endocrine cell hyperplasia. World Journal of Gastroenterology 17 137-143. (doi:10.3748/wjg.v17.i2.137)

Petersen KF \& Sullivan JT 2001 Effects of a novel glucagon receptor antagonist (Bay 27-9955) on glucagon-stimulated glucose production in humans. Diabetologia 44 2018-2024. (doi:10.1007/ s001250100006)

Quesada I, Tudurí E, Ripoll C \& Nadal A 2008 Physiology of the pancreatic $\alpha$-cell and glucagon secretion: role in glucose homeostasis and diabetes. Journal of Endocrinology 199 5-19. (doi:10.1677/JOE-08-0290)
Qureshi SA, Rios Candelore M, Xie D, Yang X, Tota LM, Ding VD, Li Z, Bansal A, Miller C, Cohen SM et al. 2004 A novel glucagon receptor antagonist inhibits glucagon-mediated biological effects. Diabetes 53 3267-3273. (doi:10.2337/diabetes.53.12.3267)

Robben JH, Sze M, Knoers NV \& Deen PM 2006 Rescue of vasopressin V2 receptor mutants by chemical chaperones: specificity and mechanism. Molecular Biology of the Cell 17 379-386. (doi:10.1091/ mbc.E05-06-0579)

Runge S, Thøgersen H, Madsen K, Lau J \& Rudolph R 2008 Crystal structure of the ligand-bound glucagon-like peptide-1 receptor extracellular domain. Journal of Biological Chemistry 283 11340-11347. (doi:10.1074/jbc.M708740200)

Spiegel AM \& Weinstein LS 2004 Inherited diseases involving G proteins and G protein-coupled receptors. Annual Review of Medicine 55 27-39. (doi:10.1146/annurev.med.55.091902.103843)

Tao YX 2006 Inactivating mutations of $\mathrm{G}$ protein-coupled receptors and diseases: structure-function insights and therapeutic implications. Pharmacology and Therapeutics 111 949-973. (doi:10.1016/j.pharmthera.2006.02.008)

Underwood CR, Garibay P, Knudsen LB, Hastrup S, Peters GH, Rudolph R \& Reedtz-Runge S 2010 Crystal structure of glucagonlike peptide-1 in complex with the extracellular domain of the glucagon-like peptide-1 receptor. Journal of Biological Chemistry 285 723-730. (doi:10.1074/jbc.M109.033829)

Unson CG, Cypess AM, Kim HN, Goldsmith PK, Carruthers CJ, Merrifield RB \& Sakmar TP 1995 Characterization of deletion and truncation mutants of the rat glucagon receptor. Seven transmembrane segments are necessary for receptor transport to the plasma membrane and glucagon binding. Journal of Biological Chemistry 270 27720-27727. (doi:10.1074/jbc.270.46.27720)

Unson CG, Wu CR, Jiang Y, Yoo B, Cheung C, Sakmar TP \& Merrifield RB 2002 Roles of specific extracellular domains of the glucagon receptor in ligand binding and signaling. Biochemistry 41 11795-11803. (doi:10.1021/bi025711j)

Webb GC, Akbar MS, Zhao C, Swift HH \& Steiner DF 2002 Glucagon replacement via micro-osmotic pump corrects hypoglycemia and $\alpha$-cell hyperplasia in prohormone convertase 2 knockout mice. Diabetes 51 398-405. (doi:10.2337/diabetes.51.2.398)

Winzell MS, Brand CL, Wierup N, Sidelmann UG, Sundler F, Nishimura E \& Ahrén B 2007 Glucagon receptor antagonism improves islet function in mice with insulin resistance induced by a high-fat diet. Diabetologia 50 1453-1462. (doi:10.1007/s00125-0070675-3)

Yan H, Gu W, Yang J, Bi V, Shen Y, Lee E, Winters KA, Komorowski R, Zhang C, Patel JJ et al. 2009 Fully human monoclonal antibodies antagonizing the glucagon receptor improve glucose homeostasis in mice and monkeys. Journal of Pharmacology and Experimental Therapeutics 329 102-111. (doi:10.1124/jpet.108.147009)

Yu R, Nissen NN, Dhall D \& Heaney AP 2008 Nesidioblastosis and hyperplasia of $\alpha$ cells, microglucagonoma, and nonfunctioning islet cell tumor of the pancreas. Pancreas 36 428-431. (doi:10.1097/MPA. 0b013e31815ceb23)

Yu R, Wawrowsky K \& Zhou C 2011 a A natural inactivating mutant of human glucagon receptor exhibits multiple abnormalities in processing and signaling. Endocrinology and Nutrition 58 258-266. (doi:10.1016/j.endonu.2011.04.002)

Yu R, Dhall D, Nissen NN, Zhou C \& Ren SG $2011 b$ Pancreatic neuroendocrine tumors in glucagon receptor-deficient mice. PLoS ONE 6 e23397. (doi:10.1371/journal.pone.0023397)

Zhou C, Dhall D, Nissen NN, Chen CR \& Yu R 2009 Homozygous P86S mutation of the human glucagon receptor is associated with hyperglucagonemia, $\alpha$ cell hyperplasia, and islet cell tumor. Pancreas 38 941-946. (doi:10.1097/MPA.0b013e3181b2bb03)

Received in final form 17 May 2012

Accepted 8 June 2012

Made available online as an Accepted Preprint 12 June 2012 